Article

\title{
Effect of the Orientation Schemes of the Energy Collection Element on the Optical Performance of a Parabolic Trough Concentrating Collector
}

\author{
Majedul Islam 1,2 (D), Prasad Yarlagadda ${ }^{1}$ and Azharul Karim ${ }^{1, *(D)}$ \\ 1 Science and Engineering Faculty, Queensland University of Technology, Brisbane CBD, QLD 4001, Australia; \\ i.majedul@qut.edu.au or murad99me@yahoo.com (M.I.); y.prasad@qut.edu.au (P.Y.) \\ 2 Department of Mechanical Engineering, Chittagong University of Engineering \& Technology, \\ Chittagong 4349, Bangladesh \\ * Correspondence: azharul.karim@qut.edu.au; Tel.: +61-7-31386879; Fax: +61-7-31381529
}

Received: 28 November 2018; Accepted: 27 December 2018; Published: 31 December 2018

check for updates

\begin{abstract}
While the circular shape is currently the proven optimum design of the energy collection element (ECE) of a parabolic trough collector, that is yet to be confirmed for parabolic trough concentrating collectors (PTCCs) like trough concentrating photovoltaic collectors and hybrid photovoltaic/thermal collectors. Orientation scheme of the ECE is expected to have significant effect on the optical performance including the irradiance distribution around the ECE and the optical efficiency, and therefore, on the overall energy performance of the PTCC. However, little progress addressing this issue has been reported in the literature. In this study, a thorough investigation has been conducted to determine the effect of the orientation schemes of ECE on the optical performance of a PTCC applying a state-of-the-art Monte Carlo ray tracing (MCRT) technique. The orientation schemes considered are a flat rectangular target and a hollow circular, semi-circular, triangular, inverted triangular, rectangular and rectangle on semi-circle (RSc). The effect of ECE defocus, Sun tracking error and trough rim angle on the optical performance is also investigated. The MCRT study reveals that the ECE orientation schemes with a curved surface at the trough end showed much higher optical efficiency than those with a linear surface under ideal conditions. ECEs among the linear surface group, the inverted triangular orientation exhibited the highest optical efficiency, whereas the flat and triangular ones exhibited the lowest optical efficiency, and the rectangular one was in between them. In the event of defocus and tracking errors, a significant portion of the concentrated light was observed to be intercepted by the surfaces of the rectangular and RSc ECEs that are perpendicular to the trough aperture. This is an extended version of a published work by the current authors, which will help to design an optically efficient ECE for a parabolic trough concentrating collector.
\end{abstract}

Keywords: concentrating solar power; parabolic trough concentrating collector; optical performance; optical efficiency; irradiance distribution; Monte Carlo ray tracing

\section{Introduction}

Rapid depletion of fossil fuels, global warming and ecological imbalance are driving society to use green and renewable alternatives like solar energy. Efficient harnessing of this vast energy sources has the potential to fulfil the world's energy demand [1-3]. A significant amount of research has already been undertaken to develop technologies for harnessing this abundant energy source [4-16]. Concentrating solar power technologies including the PTCC, parabolic dish, linear Fresnel reflector and heliostat field are competitive candidates to the conventional sources in terms of carbon emissions though the investment cost is still higher [17]. 
A PTCC can be used for collecting thermal energy using a parabolic trough collector (PTC) [13,18-20], electrical energy using a concentrating photovoltaic collector (TCPV) with passive cooling system [21,22] or combined thermal and electrical energy using a concentrating photovoltaic/thermal collector (TCPVT) with an active cooling system [23-26]. Usually a PTCC is fabricated placing an energy collection element (ECE) along the focal line of a parabolic trough mirror. While the geometry of the ECE of a PTC collector is generally tubular $[18,26]$, that of the CPV collector is flat and rectangular with a heat sink [21,22] and CPVT collectors are either flat rectangular [23], hollow inverted triangular [27-29] or tubular [26] with a heat transfer fluid (HTF) passage. The overall energy performance of a PTCC relies directly on the optical performance, particularly on the irradiance distribution at the receiver aperture [30-32] and optical efficiency [33,34] of the collector. Overall design or geometry of the ECE has significant influence on the irradiance distribution and optical efficiency of the collector is expected. Past research mostly focused on the measurement techniques of the optical performance of the PTC, particularly the irradiation distribution around the receiver and intercept factors.

The first qualitative study on available energy and its distribution at the focal plane of the parabolic concentrator was carried out by Hassan and El-Refaie [35]. Using "cone optics", a similar study was conducted quantitatively by Evans [36] in 1977. He has derived an integral expression to evaluate the irradiance profile of a parabolic trough flat collector using three different solar models: uniform disk, uniform square and non-uniform disk. Daly [37] produced almost the similar irradiance profile for a uniform and non-uniform solar disk applying backward ray tracing method. Nicolás and Durán [38] described a 2D optical analysis technique for a parabolic trough concentrating flat collector, which is applicable for all incidence angles of the solar rays. They further extended the same work for non-perfect concentrators [39]. Exploiting the geometrical symmetry of a parabolic trough concentrator, Jeter [40-42] first proposed a semi-finite formula to yield the concentrated radiant flux density distribution at the focal plane and around a tubular ECE of a PTC. Thomas and Guven [34] and Kalogirou [43] studied the effect of optical errors on irradiance distribution around the ECE of PTC and observed a significant effect of total optical errors on optical efficiency and intercept factor. Dudley et al. [18] measured the near optical efficiency of the Luz Solar 2 (LS2) collector at the AZTRAK rotating platform of Sandia National Laboratory used in Solar Energy Generating Systems III-VII 150 MW plants, Kramer Junction (CA, USA). Shortis and Johnston adopted a mix experimental and analytical photogrammetry technique for three dimensional characterization [44] and assessment of the quality of the surface [45] of the parabolic dish of the ANU $400 \mathrm{~m}^{2}$ "Big Dish" project. The photogrammetry method allows measuring 3D coordinates of any surface including parabolic shape with precision 1:50,000 or better, and the data to be used for calculating slope errors of the measured surface and intercept factors. The precision of the technique was further demonstrated in the EuroTrough project [46]. Riffelmann et al. [47] developed PARASCAN (PARAbolic Trough Flux SCANner) and Camera Target Method for flux mapping at the focal line of a PTC. Coventry [23] measured flux profile at the focal plane and investigated the slope error of the parabolic trough of the ANU CHAPS system traversing a water cooled $50 \mathrm{~mm}$ long solar cell using "Skywalker" along the focal line of the mirror. Ergashev [48] developed a computer program adopting the ancient Aparisi model to simulate the irradiance profile statistically at the PTC focal plane, which enables a 3D plot of the profile. Lüpfert et al. [49] applied photogrammetry, flux mapping, ray tracing and advanced thermal testing on their EuroTrough collectors, and achieved consistent results in collector shape measurement, flux measurement and thermal performance for all four testing methods. Bader and Steinfeld [50] used an integral methodology and developed an exact profile of a tailored solar trough concentrator to achieve a uniform 'pill-box' irradiance profile over a flat rectangular target. They performed an MCRT study to investigate the effect of sunshape and mirror imperfections on the distribution and spillage. In 2009 and onward, a great deal of studies were undertaken by researchers including Ze-Dong Cheng applying MCRT technique to investigate the optical efficiency and the irradiance distribution around 
the absorber tube of the ECE of a PTC, and in some of these studies, the MCRT model was coupled with CFD model to investigate the conjugate heat and mass transfer phenomena of the ECE [51-61].

Grena [52] developed a 3D ray tracing model for a parabolic trough collector and computed the total optical efficiency, distribution of the absorbed radiation around the ECE and energy absorbed by the glass cover. Yang et al. [53] developed a MCRT probabilistic model and calculated local concentration ratio (LCR) profile around a circular receiver for non-parallel sun rays, tracking error, rim angle and geometric concentration (GC). Jiang et al. [54] proposed a two-stage parabolic trough concentrating photovoltaic/thermal collector system using beam splitting filter and solar cells. Applying the MCRT technique, they found that up to $76 \%$ overall optical efficiency of the collector could be achieved, $10.5 \%$ heat can be recovers and $20.7 \%$ heat load of the solar cell can be reduced. Cheng et al. [55] coupled a MCRT model with a 3D finite volume model (FVM), and investigated coupled heat transfer mechanism in and energy loss from the outer surface of the circular absorber tube of a PTC. Similar photo-thermal simulation study was undertaken by He at al. [57] the following year for the ECE of a PTC. They investigated the effect of rim angles and geometric concentrations on the irradiance distribution around the circular ECE. Cheng et al. [58] further extended their theoretical study for the complete ECE of their PTC, and investigated the performance of different HTFs and the effect of the condition of the annular space between the absorber tube and the glass cover on the energy loss of the ECE. They further increased the robustness of their coupled photo-thermal simulation model enabling MCRT modeling of three typical concentrating collectors systems include PTC, parabolic dish and REFOS-SOLGATE modular pressurized volumetric receiver [59]. The MCRT coupled FVM was further adapted to investigate optical and thermal performance of different commercial PTC collector systems including LAT73 Trough, Siemens UVAC 2010 and T6R4 [60]. A similar study was undertaken by Wang et al. [61] for the ECE of a PTC, and they applied the finite element method instead of the FVM method for the CFD modeling. Zou et al. [62] developed a detailed MCRT model, and extensive study was undertaken to investigate the effect of geometrical parameters (including trough aperture width, focal length and ECE diameter), related critical parameters (rays escaping effect, shading effect, angle span of flux distribution region and non-uniformity of flux distribution) and size relationship between the reflected light cone and the ECE diameter. Beside these photo-thermal performance study of the circular ECE of a PTC, there are few other studies that investigated the total energy (electrical and/or thermal) performance of different ECE orientation schemes including a flat, inverted triangular and circular for the PTCC [21-26].

However, none of above studies was related to the effect of ECE orientation schemes on the optical performance of PTCC except the following one. Kabakov and Levin [63] analytically investigated three ECE orientation schemes: a slit channel, a quadrate channel and a non-regular six sided polyhedron in order to investigate the uniformity of the solar flux distribution along the ECEs' perimeter. Ignoring the ECE shading on the trough and tracking error, they noticed that the polyhedron orientation would produce satisfactorily uniform irradiance distribution. Therefore, it is highly desirable and timely to investigate the effect of orientation scheme of the ECE of a PTCC on its optical performance.

In a published paper by the current authors, investigation of the effect of physical and optical factors on the optical performance of a parabolic trough collector applying MCRT technique was presented [64]. Current study extends that work to investigate the effect of ECE orientation schemes including a flat rectangular target, circular, semicircular, triangular, inverted triangular, rectangular and rectangle on semicircle (RSc) on the optical performance of a PTCC as detailed in this article. By the authors' best knowledge, this is the first study on this specific topic applying MCRT technique. Development and validation of the MCRT model is summarized first, which was then adapted for different geometry and investigated the effect of irradiance distribution and optical efficiency. The MCRT model was verified against measured optical efficiency of LS2 collector [18] and analytical flux profile of Jeter's collector $[40,42]$. The Zemax ${ }^{\circledR}$ optical ray tracing software was used for this study [65]. 


\section{MCRT Simulation}

\subsection{Physical Model}

To facilitate direct validation of the MCRT model with measured optical efficiency, a proven and widely used parabolic trough collector, Luz Solar II (LS2), was modelled in this study. The LS2 collector was used in the Solar Energy Generating System III-VII 150 MW plants, Kramer Junction, (CA, USA). It was tested on the AZTRAK rotating platform at Sandia National Laboratory [18]. Figure 1a,b show the cross-sectional views of the collector and the ECE of the LS2 collector. The geometry and the optical properties of the collector components are given in Table 1. A closed-end plug was inserted in the tube of the collector to increase the flow velocity of the Syltherm 800 silicone oil heat transfer fluid (HTF). If the difference between the HTF mean working temperature and the ambient temperature is very low, the heat loss from the receiver is negligible, and the collected thermal energy is almost equal to that of the absorbed optical energy by the receiver.

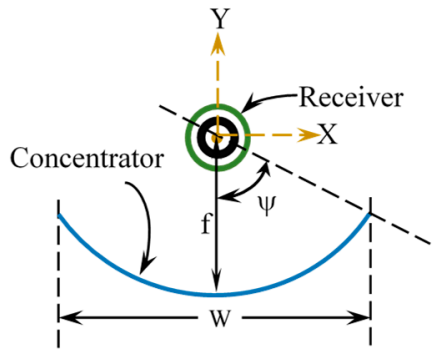

(a)

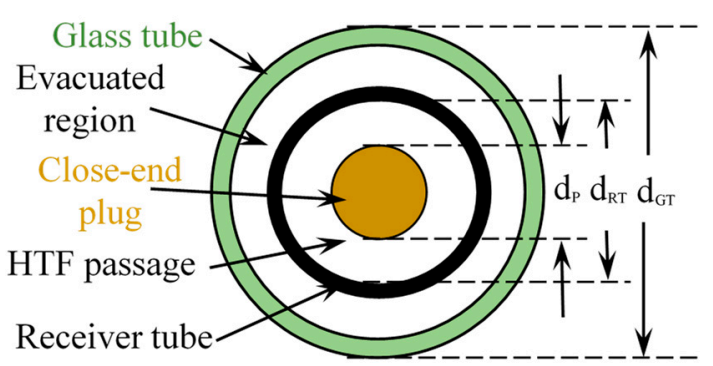

(b)

Figure 1. Cross-sectional views of (a) the Luz Solar 2 collector and (b) the ECE geometry. (The design parameters are given in Table 1).

Table 1. Geometric configuration, optical properties and loss factors of the Luz Solar 2 parabolic trough collector [19].

\begin{tabular}{ll}
\hline Parameters & Value \\
\hline Concentrator width, $\mathrm{W}=$ & $5 \mathrm{~m}$ \\
Concentrator length, $\mathrm{L}_{\mathrm{PT}}=$ & $7.8 \mathrm{~m}$ \\
Receiver length, $\mathrm{L}_{\mathrm{RT}}=$ & $8 \mathrm{~m}$ \\
Rim angle, $\psi=$ & $\approx 68^{\circ}$ \\
Focal length, $\mathrm{f}=$ & $1.84 \mathrm{~m}$ \\
Close-end plug outer diameter, $\mathrm{d}_{\mathrm{P}}=$ & $50.8 \mathrm{~mm}$ \\
Glass tube outside diameter, $\mathrm{d}_{\mathrm{GT}}=$ & $115 \mathrm{~mm}$ \\
Glass tube thickness, $\mathrm{t}_{\mathrm{GT}}=$ & $3 \mathrm{~mm}$ \\
Receiver tube inside diameter, $\mathrm{d}_{\mathrm{RT}}=$ & $66 \mathrm{~mm}$ \\
Receiver tube thickness, $\mathrm{t}_{\mathrm{RT}}=$ & $2 \mathrm{~mm}$ \\
Concentrator reflectance, $\varrho_{\mathrm{PT}}=$ & 0.9337 \\
Glass tube transmittance, $\tau_{\mathrm{GT}}$, & \\
for evacuated condition $=$ & 0.935 \\
and for bare receiver $=$ & 1.0 \\
Receiver absorptance, $\alpha_{\mathrm{RT}}$, for & \\
(mostly used) cermet selective coating $=$ & 0.92 \\
black chrome selective coating (used for the current MCRT model) & 0.94 \\
Tracking error factor, $\mathrm{E}_{\sigma}=$ & 0.994 \\
Geometry error factor, Egeom $=$ & 0.98 \\
General error factor, $\mathrm{E}_{\text {gen }}=$ & 0.96 \\
Optical loss factor for $\mathrm{F}_{\text {Dirt_on_RT }}=$ & 0.981 \\
Optical loss factor for $\mathrm{F}_{\text {Dirt_on_PT }}=$ & 0.963 \\
\hline
\end{tabular}

In the table, suffix PT, RT, P, GT, max, min, $\sigma$, geom and gen refer the parabolic trough, receiver tube, close ends plug as flow restriction device, glass tube, maximum, minimum, sigma, geometry and general respectively. 
Relying on this assumption, near optical efficiency of the LS2 collector was measured for different conditions [18]. Several test conditions were chosen for the current MCRT model as presented in Table 2. The support structure was ignored in the MCRT model.

Table 2. Selected test conditions of LS-2 collector for the MCRT model from Dudley et al. [18].

\begin{tabular}{cccccc}
\hline S1 No. & DNI $\left(\mathbf{W} / \mathbf{m}^{\mathbf{2}}\right)$ & Selective Coatings & Glass Tube Condition & $\eta_{\text {opt }}(\mathbf{\%})$ & $\mathbf{E}_{\text {est }}(\mathbf{\%})$ \\
\hline 1 & 807.9 & Cermet & Vacuum & 72.63 & 1.91 \\
2 & 925.1 & Cermet & Air filled & 73.68 & 1.96 \\
3 & 954.5 & Cermet & Removed & 77.5 & - \\
4 & 850.2 & Black Chrome & Vacuum & 73.1 & 2.36 \\
\hline
\end{tabular}

In the table, DNI, $\eta$ and E stand for Daily Normal Irradiation, Efficiency and Error. The suffixes opt and est mean optical and estimated data.

\subsection{Ray Tracing Technique}

The cylindrical coordinate system, $\mathrm{r} \beta Z$, was used for circular surfaces and the Cartesian coordinate system, XYZ, was used for the rest of the collector components including the trough. The LS2 collector was modelled as per the design presented in Table 1. In order to minimise the computational expense, following assumptions were made:

(a) The irradiance distribution varies across the axis and uniform along the axis of the ECE. Therefore, the length of the modelled collector was $50 \mathrm{~cm}$.

(b) The trough was locally specularly reflective, and the light incident was perpendicular on the trough aperture.

(c) No shading from the frame and brackets.

(d) No structural deformities in the trough and the receiver.

(e) Diffuse light is negligible.

A biconic surface for the parabolic trough (PT) and two concentric annular volume objects for the receiver tube (RT) and the glass tube (GT) from the object library were adapted to model the collector system. Enabling 'surface coating' option, a specular reflectance of the mirror, glass transmittance with anti-reflection coating and light absorptance with black chrome spectral selective coatings on the ECE material were developed (refer to Table 1 ). In addition to these, incidence angle $\left(\theta^{\circ}\right)$ depended light absorptance $(\alpha)$ in the ECE material was also considered in the model, such that the actual light absorptance at the point of incidence was $\alpha \cos \theta$. The ray-tracing algorithm and the light interaction among the components are presented in Figure $2 \mathrm{a}, \mathrm{b}$, respectively.

The steps in Figure 2a are self-explanatory; the rhombuses and rectangles in the flow chart represent the arguments and Monte Carlo decision of the arguments respectively. The Monte Carlo decision was based on the sunshape, optical properties and geometry of the collector components, and the laws of reflection and refraction. The azimuth angle and the deflection angle of the modelled sunshape, $I(\varphi)$, (see Equation (1) [66-68]) were $2 \pi$ and $0.266^{\circ}$ respectively. The incident location and the direction vectors of the rays are denoted by $\mathrm{P}\left(\mathrm{P}_{\mathrm{x}}, \mathrm{P}_{\mathrm{y}}, \mathrm{P}_{\mathrm{z}}\right)$ and $\mathrm{D}\left(\mathrm{D}_{\mathrm{x}}, \mathrm{D}_{\mathrm{y}}, \mathrm{D}_{\mathrm{z}}\right)$ respectively. Considering a mean absolute error of $0.08-0.1 \%$ in the concentrator reflectance and the glass transmittance, $5 \times 10^{7}$ to $10^{8}$ rays $/ \mathrm{m}^{2}$ of aperture area of the collector were traced for the model. A grid sensitivity test was carried out, and it was observed that the final MCRT result significantly varied with the variation of the number of rays instead of the grid of the collector components. As the irradiance distribution varies across the axis and uniform along the axis as assumed, the width $\times$ length of each grid was $1.32 \mathrm{~mm} \times 12.5 \mathrm{~mm}$. Light reflection on the mirror and transmission through the glass were followed by Fresnel's law, Equation (2), and Snell's law, Equation (3).

$$
\mathrm{I}(\varphi)=\frac{\cos \left(\frac{0.05868 \varphi}{\pi}\right)}{\cos \left(\frac{0.05868 \varphi}{\pi}\right)}
$$

where, $\varphi$ is the deflection angle. 


$$
\begin{gathered}
D_{\mathrm{PT}}=\mathrm{D}_{\mathrm{n}}-2\left(\mathrm{~N}_{\mathrm{PT}} \cdot \mathrm{D}_{\mathrm{n}}\right) \mathrm{N}_{\mathrm{PT}} \\
\mathrm{D}_{\mathrm{GT}}=\mathrm{D}_{\mathrm{PT}}-\left(\mathrm{N}_{\mathrm{GT}} \cdot \mathrm{D}_{\mathrm{PT}}\right) \mathrm{N}_{\mathrm{GT}}+\sqrt{\left(\mathrm{n}_{\mathrm{GT}}\right)^{2}-\left(\mathrm{n}_{\mathrm{air}}\right)^{2}+\left(\mathrm{N}_{\mathrm{GT}} \cdot \mathrm{D}_{\mathrm{PT}}\right)^{2} \mathrm{~N}_{\mathrm{GT}}}
\end{gathered}
$$

where, $\mathrm{D}, \mathrm{N}, \mathrm{n}_{\mathrm{GT}}$ and $\mathrm{n}_{\mathrm{air}}$ are the direction vector, normal vector, and refractive indices of the glass and air respectively. The normal vectors, $\mathrm{N}_{\mathrm{PT}}$ and $\mathrm{N}_{\mathrm{GT}}$ were calculated from Equations (4) and (5) respectively:

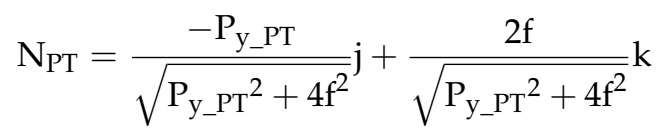

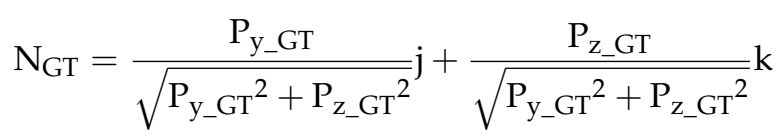

where, $\mathrm{P}$ is the incident points of the rays in Cartesian coordinate system and $\mathrm{f}$ is focal length of the mirror.

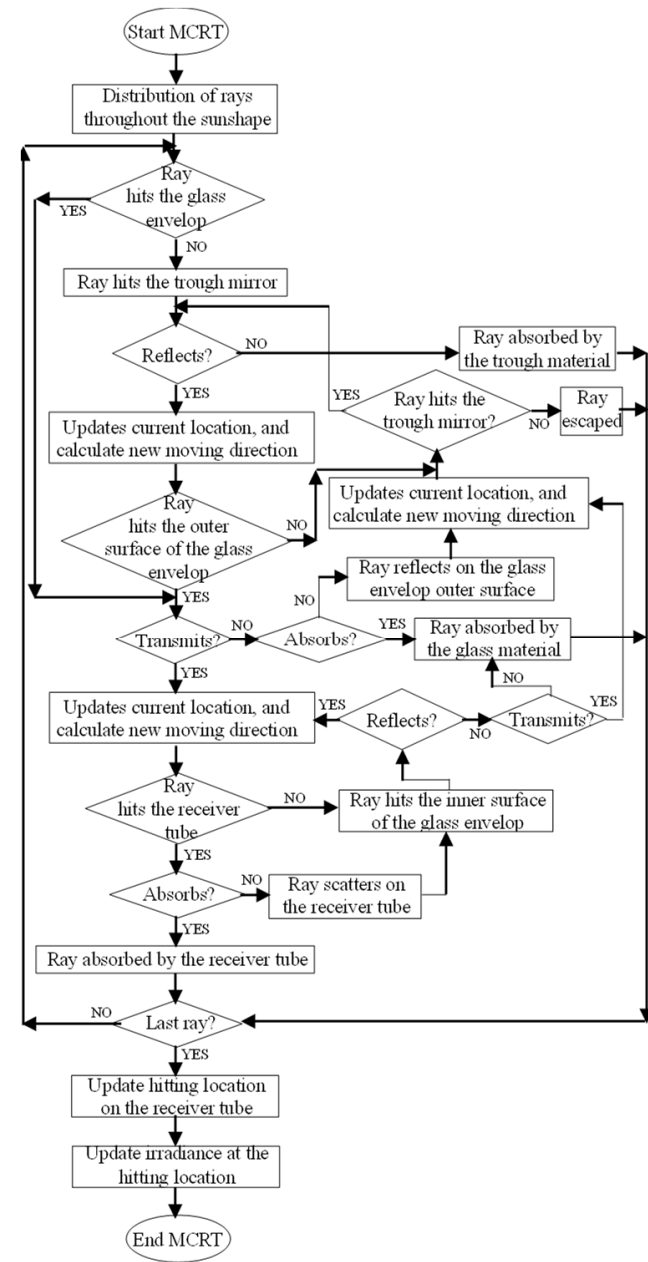

(a)

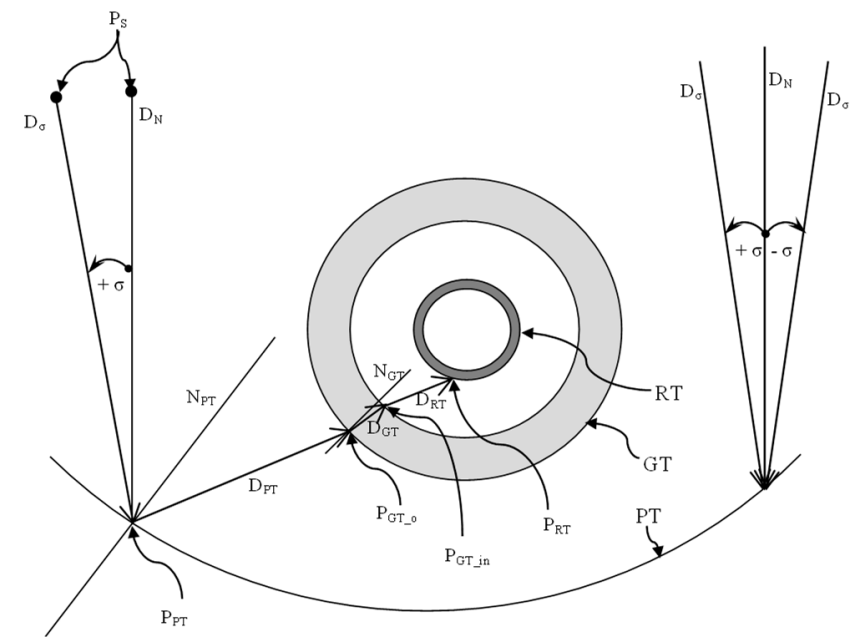

(b)

Figure 2. Algorithm for the Monte Carlo ray tracing model of LS2 Collector: (a) flowchart and (b) direction vectors of the incident rays (In the figure, $\mathrm{P}, \mathrm{D}$ and $\mathrm{N}$ denote light incident points, direction vector and normal vector respectively; suffixes, s, $\sigma, \mathrm{N}, \mathrm{PT}, \mathrm{GT}, \mathrm{RT}$, o and 'in' denote sun, tracking error in degree, normal, parabolic trough, glass tube, receiver tube, outer or outside and inner or inside respectively). 


\subsection{Validation of the Model}

The selected test conditions (see Table 2) were modelled, and optical efficiencies were calculated using the current MCRT model and compared against the measured ones as shown in Figure 3a. On the other hand, the irradiation distribution around the receiver surface was verified with Jeter's published analytical model for an ideal collector of $20 \times$ geometric concentration (GC) and $90^{\circ}$ rim angle [40-42]. Jeter calculated local concentration ratio (LCR) (see Equation (6)):

$$
\begin{gathered}
\mathrm{LCR}=\frac{\mathrm{I}(1)}{\mathrm{DNI} \times \mathrm{C}_{\mathrm{opt}}} \\
\mathrm{C}_{\mathrm{opt}}=\rho_{\mathrm{PT}} \times \tau_{\mathrm{GT}} \times \alpha_{\mathrm{RT}}
\end{gathered}
$$

where, $\mathrm{I}(\mathrm{l})$ is local irradiance, 1 is any point on the concerned surface of the ECE and $\mathrm{C}_{\mathrm{opt}}$ is product of collector optical properties and other factors.

For the Jeter's collector, $\mathrm{C}_{\text {opt }}$ was considered unity, the daily normal irradiation (DNI) was $1 \mathrm{~kW} / \mathrm{m}^{2}$ and solar disk was $7.5 \mathrm{mrad}$. LCR profile calculated using Jeter's analytical model and current MCRT model with and without glass envelop around the receiver tube are shown in Figure $3 \mathrm{~b}$. Our model slightly overestimates the optical efficiency (see Figure 3a) which is reasonable given the simplifying assumptions and experimental error because of incident angle modifier in the measured near optical efficiency calculated by Dudley et al. [18] (see the last column in Table 2). Figure 3b shows an excellent match between the LCR profiles calculated using the current MCRT model and Jeter's analytical model. So, it can be claimed that the current MCRT model is validated.

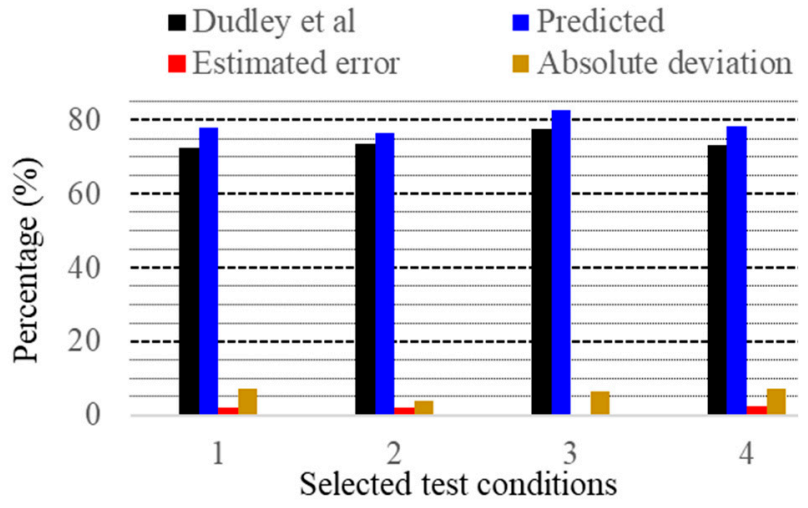

(a)

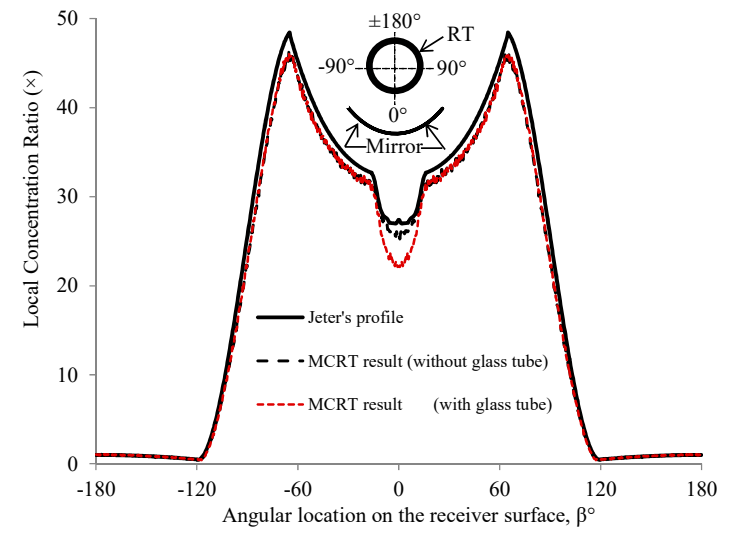

(b)

Figure 3. Validation of the MCRT model. (a) MCRT calculated optical efficiencies and the absolute deviations with the measured values and (b) Comparison of calculated LCR profiles around the receiver tube (RT) of a typical PTC with Jeter's LCR profile [63].

\section{Geometry of the Studied ECE Orientation Schemes}

The orientation scheme of the ECE of the validated MCRT model was adapted for different geometric configurations including a circular, semicircular, flat, triangular, inverted triangular, rectangular and Rectangle-on-Semicircular (RSc) as shown in Figure 4. The cross section of each scheme is shown in the figure. The rim angle, optical properties of the collector and the projected area of each ECE were equal to those of the LS2 collector (see Table 1). By this way, their geometric concentrations (=trough aperture width/ECE outer perimeter) are calculated as 24.1, 29.46, 75.76, 32.05, $32.05,18.94$ and 21.22 respectively with a $5 \mathrm{~m}$ wide trough. The glass envelope was not considered in this study. Usually a part of the outer periphery of these receivers are irradiated from concentrated light from the trough, a part from the direct Sun, and the rest remains shaded. All these ECEs, except 
the circular one, consist of one or more plain surfaces. Depending on the relative positions between the ECE and the trough, these surfaces were named: Trough See Surface (TSS), Trough No-see Surface (TNS) and Trough Partially-see Surface or perpendicular to the trough aperture (TPS) as shown in Figure 4. Respective LCR profile and optical efficiency were calculated applying the MCRT model detailed in the following section.

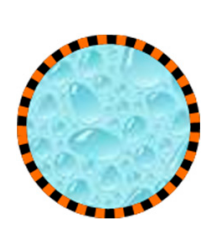

(a)

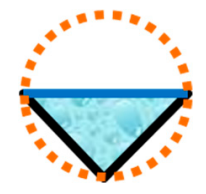

(e)

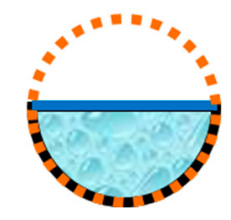

(b)

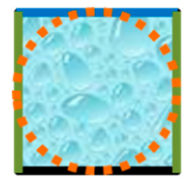

(f)

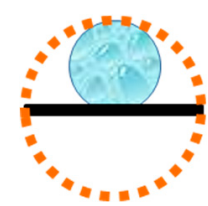

(c)

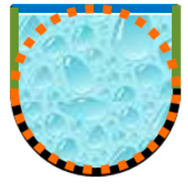

$(\mathrm{g})$

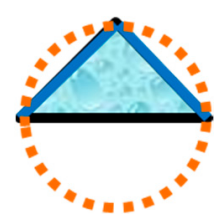

(d)

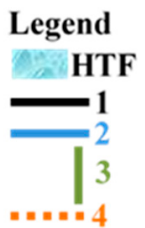

(h)

Figure 4. Schematic diagram of the studied orientation schemes of ECE: (a) circular, (b) semicircular, (c) flat, (d) triangular, (e) inverted triangular, (f) rectangular (g) rectangle on semi-circle (RSc) and (h) the legend used in the figure. In the legend, HTF = Heat Transfer Fluid, $1=$ Trough See Surface (TSS), 2 = Trough No-see Surface (TNS), 3 = Trough Partially see-Surface (TPS) (perpendicular to the trough aperture), and $4=$ outline of LS2 receiver of inside diameter $66 \mathrm{~mm}$. By this way, the projected area of each receiver on the trough aperture is equal.

\section{Calculated LCR Profile around the ECEs and Respective Optical Efficiency}

Local irradiance around the ECE was estimated using the current MCRT model, and LCR profile across the respective surfaces was calculated using (6). From the LCR profile, peak light concentration $\left(C_{\text {peak }}\right)$, base concentration $\left(C_{\text {base }}\right.$, mean concentration $\left(C_{\text {mean }}\right)$ and mean absolute deviation (MAD) of each surface, and optical efficiency $\left(\eta_{\text {opt }}\right.$ ) of each ECE were calculated using the Equations (8)-(10).

$$
\begin{gathered}
\mathrm{C}_{\mathrm{avg}}=\frac{\Sigma(\Delta \mathrm{w} \times \mathrm{LCR})}{\Sigma \Delta \mathrm{w}} \\
\mathrm{MAD}=\frac{\Sigma\left|\mathrm{LCR}-\mathrm{C}_{\mathrm{avg}}\right|}{\mathrm{n}} \\
\eta_{\text {opt }}=\frac{\left\{\Sigma\left(\mathrm{C}_{\mathrm{avg}} \times \mathrm{w}\right)\right\} \times \mathrm{DNI} \times \mathrm{C}_{\mathrm{opt}}}{\mathrm{W}} \times 100 \%
\end{gathered}
$$

where, $\Delta \mathrm{w}$ was the grid width and $\mathrm{n}$ was the number of grids or data points across each surface of the ECE, and W was the aperture width of the trough. As the glass envelop was not modelled, the transmittance was assumed unity. The aperture width was $5 \mathrm{~m}$ for a $68^{\circ}$ rim angle collector and $7.36 \mathrm{~m}$ for a $90^{\circ}$ rim angle collector. The lengths of the trough and the ECE were equal. The MCRT results of each ECE orientation scheme are discussed in the following subsections.

\subsection{Circular}

This is the most common and proven ECE geometry of a PTC. However, a circular ECE for a TCPVT collector can be made using flexible solar cells or arranging PV facets in circular orientation [26]. The entire circumference of the receiver tube was considered as the TSS, and the trough focus is considered along the ECE axis. The LCR profile is generally somewhat " $\mathrm{M}$ " shaped, bi-symmetric with double peaks $\left(\mathrm{C}_{\text {peak }} \approx 63.5 \times\right)$ with $\mathrm{C}_{\text {mean }} \approx 22 \times$ as shown in Figure 5 . Almost half 
of the outer surface of the circular ECE is away from the trough that makes complete shading $\left(C_{\text {base }}=0\right)$ with high MAD $(\approx 23.7)$ as presented in Table 3. The optical efficiency of a circular ECE was estimated to be about $80 \%$.

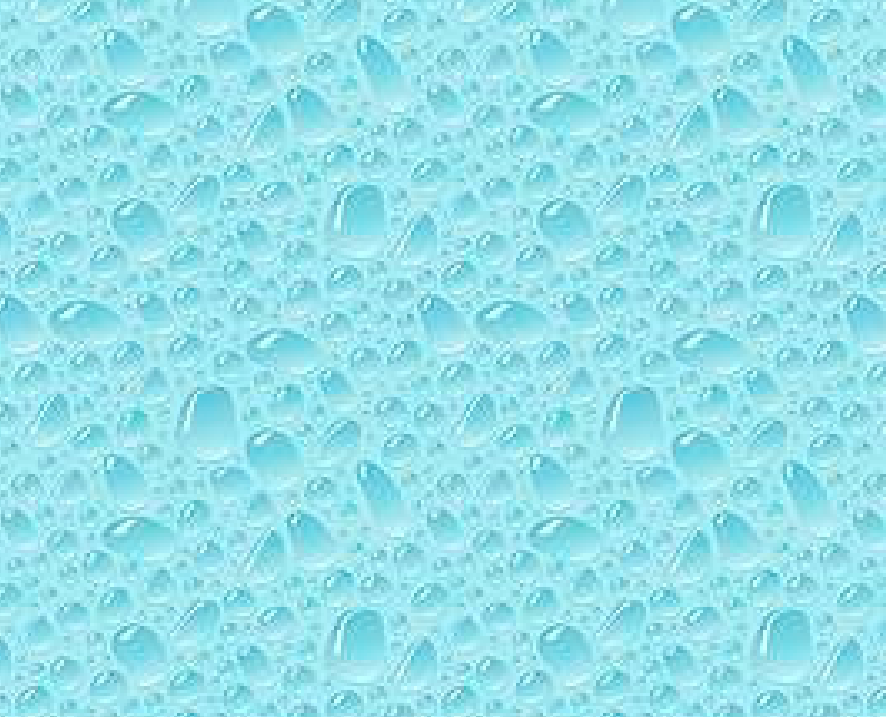

Figure 5. LCR profiles of the TSS of a circular, semicircular and flat ECE.

Table 3. Optical performances of the circular, semicircular and flat ECEs.

\begin{tabular}{ccccccccc}
\hline $\begin{array}{c}\text { ECE } \\
\begin{array}{c}\text { Orientation } \\
\text { Schemes }\end{array}\end{array}$ & $\begin{array}{c}\text { Location } \\
\text { of Focus } \\
(\mathbf{(})\end{array}$ & $\begin{array}{c}\mathbf{C}_{\text {base }} \\
(\times)\end{array}$ & $\begin{array}{c}\mathbf{C}_{\text {peak }} \\
(\times)\end{array}$ & $\begin{array}{c}\mathbf{C}_{\text {mean }} \\
(\times)\end{array}$ & $\begin{array}{c}\text { MAD of } \\
\text { the TSS }\end{array}$ & $\eta_{\text {TSS }}(\%)$ & $\eta_{\text {TNS }}(\%)$ & $\begin{array}{c}\eta_{\text {opt }}=\Sigma \eta \\
(\%)\end{array}$ \\
\hline Circular & $\mathbf{O}$ & 0 & 63.44 & 21.85 & 23.7 & 79.56 & - & 79.56 \\
Semicircular & $\mathbf{O}$ & 1.26 & 63.44 & 43.01 & 15.46 & 78.3 & 1.02 & 79.32 \\
Flat & $\mathbf{Q}$ & 0.03 & 88 & 22.61 & 27.36 & 26.19 & - & 26.19 \\
\hline
\end{tabular}

In the table, $C_{\text {base }}, C_{\text {peak }}$ and $C_{\text {mean }}$ stand for the base, peak and mean light concentration respectively, and the MAD stand for mean absolute deviation.

\subsection{Semi-Circular}

As almost half of the outer surface of the circular ECE is away from the trough and receives direct Sun, this part can be replaced by a flat surface to make a semi-circular ECE. By this way, unlike the circular ECE, a semicircular ECE has a distinct TSS and TNS. The trough focus is still on the same location, that is toward the center of the TSS that coincide with the centerline of the TNS. However, by this way, no significant improvement in the optical efficiency could be achieved (still about $80 \%$ ). Although the actual LCR profile on the TSS of the semicircular ECE is the same (see Figure 5) of that of the circular one, since the surface (the TSS) is separated from the TNS, the MAD is dropped to $\approx 16$ (see Table 3). As the TNS gets direct sun, the optical efficiency of this surface directly depends on the optical properties of the associated components. For the investigated collector it is about $1.02 \%$.

\subsection{Flat}

A flat rectangular target at the focus of the trough with active [23] or passive cooling [21,22] system forms a flat ECE. The LCR profile is measured for the TSS assuming the trough focus onto the axis or centerline of that surface. The TNS is assumed either insulated and/or carry some form of active or passive cooling system (see Figure 4). The LCR profile was calculated to be Gaussian (see Figure 5) at ideal conditions with MAD of 27.36, while the $C_{\text {peak }}$ and $C_{\text {mean }}$ were estimated to be 
$\approx 88 \times$ and $22.61 \times$ respectively as presented in Table 3 . However, the optical efficiency of a flat ECE was predicted to be only $26.19 \%$.

\subsection{Triangular}

The LCR profile was developed for two locations of the trough focus: (i) toward the centerline of the TSS and (ii) toward the tip of the triangle as shown in Figure 6. At the first focus condition, the LCR profile of the TSS and the optical efficiency of the ECE were found almost the same to that of the flat one (see Figure 6 and Table 4$)$. The estimated $\eta_{\text {opt }}$ was marginally higher $(0.31 \%)$ only because of the direct sun on the inclined TNSs. At the second focus condition, because of defocus effect, though the $\eta_{\text {opt }}$ falls by $\approx 0.5$ point, the irradiance distribution improves significantly as the estimated MAD drops by almost $50 \%(\approx 14.6)$ with $\mathrm{C}_{\text {peak }}$ of $\approx 53 \times$.

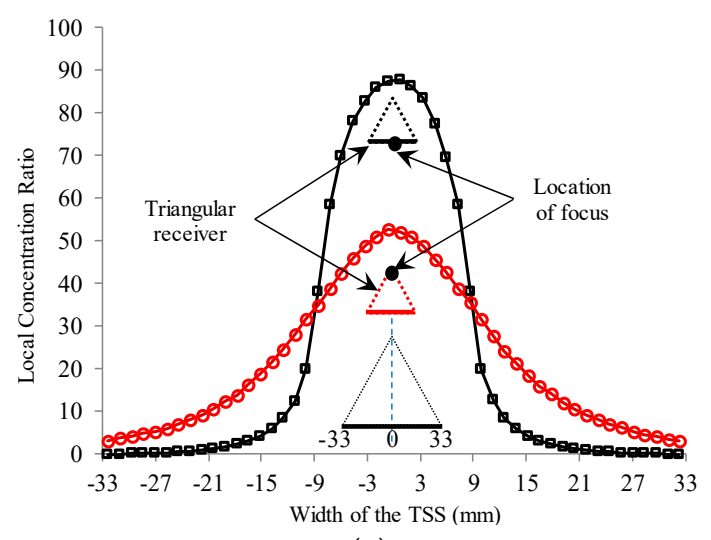

(a)

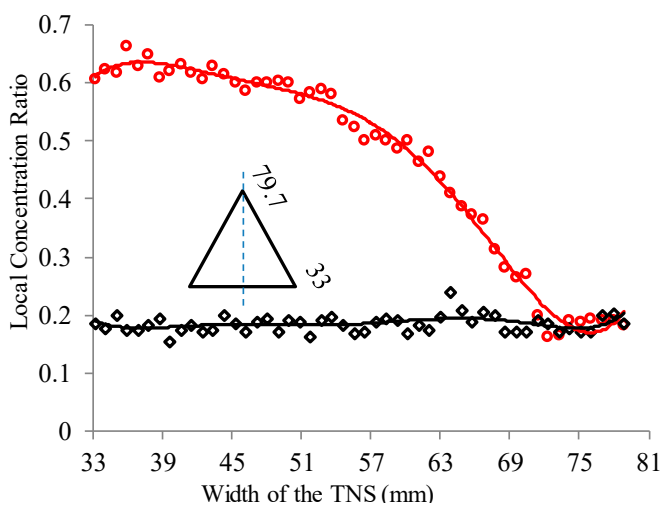

(b)

Figure 6. LCR profiles: (a) on the TSS (left) and (b) on the TNSs (right) of a triangular receiver.

Table 4. Optical performances of a triangular and an inverted triangular ECEs.

\begin{tabular}{|c|c|c|c|c|c|c|c|c|}
\hline $\begin{array}{c}\text { ECE } \\
\text { Orientation } \\
\text { Schemes }\end{array}$ & $\begin{array}{c}\text { Location } \\
\text { of Focus } \\
(0)\end{array}$ & $\begin{array}{c}C_{\text {base }} \\
(\times)\end{array}$ & $\underset{(\times)}{C_{\text {peak }}}$ & $\begin{array}{c}C_{\text {mean }} \\
(\times)\end{array}$ & $\begin{array}{l}\text { MAD of } \\
\text { the TSS }\end{array}$ & $\eta_{\text {TSS }}(\%)$ & $\eta_{\text {TNS }}(\%)$ & $\begin{array}{c}\eta_{\text {opt }}=\Sigma \eta \\
(\%)\end{array}$ \\
\hline \multirow{2}{*}{ Triangular } & & 0.03 & 88 & 22.61 & 27.36 & 26.19 & 0.31 & 26.51 \\
\hline & & 3.24 & 52.6 & 21.75 & 14.57 & 25.20 & 0.77 & 25.97 \\
\hline \multirow{3}{*}{$\begin{array}{l}\text { Inverted } \\
\text { triangular }\end{array}$} & & 0 & 63.12 & 22.42 & 21.97 & 36.37 & 1.02 & 36.99 \\
\hline & & 0.25 & 45 & 23.08 & 12 & 37.44 & 1.02 & 38.06 \\
\hline & & 5.89 & 32.2 & 20.41 & 7.35 & 33.11 & 1.02 & 33.73 \\
\hline
\end{tabular}

\subsection{Inverted Triangular}

An inverted triangular $[27,29]$ ECE has two inclined TSSs. At ideal condition with no tracking error, the LCR profiles of these two surfaces were assumed to be the mirror image of each other. The profiles were developed for three locations of the trough focus as shown in Figure 7: (a) focus toward the centroid of the triangle, (b) focus toward the centerline of the TNS (the base of the triangle) and (c) focus beyond the TNS of the triangle.

As the ECE moves toward the trough from the first location to the next and so forth, the defocus effect takes place. As a result, the $C_{\text {peak }}$ decreases gradually and moves away from the trough send of the TSS to the TNS end as shown in Figure 7. Because of the defocus effect, the MAD also decreases 
significantly from 22 to 7.3 (see Table 4). However, interestingly, the $C_{\text {mean }}$ was estimated to be the highest at the second focus condition that was $\approx 23.08 \times$ in compared to $22.42 \times$ and $20.41 \times$ for the rest of focus the conditions. The $\eta_{\text {opt }}$ was also found higher at this focus condition (see Table 4).

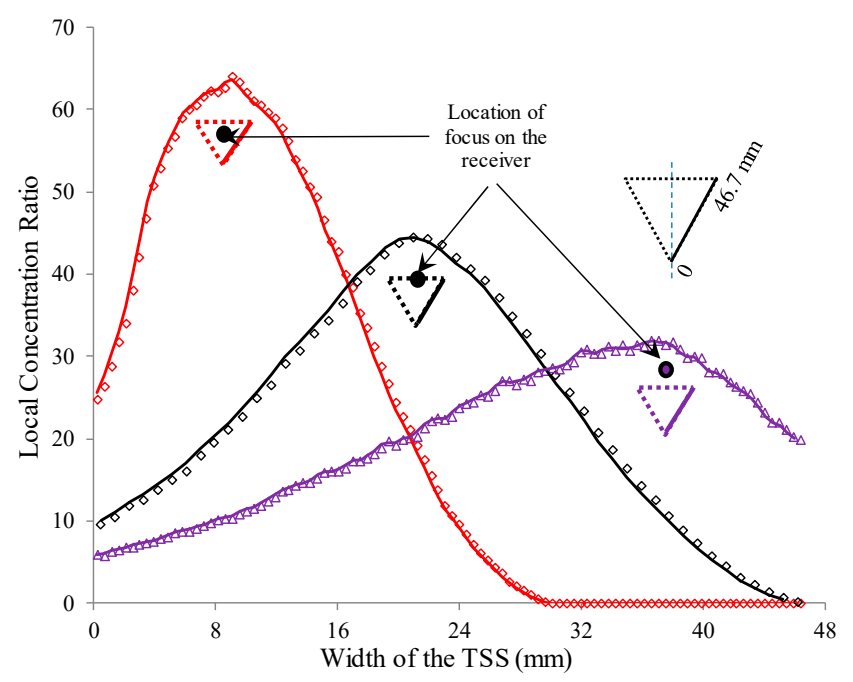

Figure 7. LCR profiles on the TSSs of an inverted triangular receiver. (In the figure red graph represents the LCR profile while the trough focus toward the centroid of the triangle, the black one represents that while the trough focus toward the TNS and the purple one represents that while the trough focus beyond the centerline of the TNS).

\subsection{Rectangular (Square)}

The LCR profile of TSS and TPSs were investigated for three locations of the trough focus on the ECE as shown in Figure 8: (i) focus toward the centroid of the rectangle, (ii) focus in middle of the centroid and the TNS and (iii) focus on the TNS.

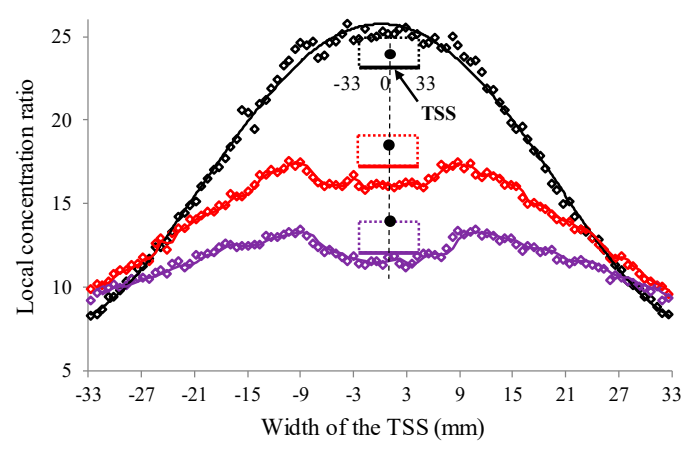

(a)

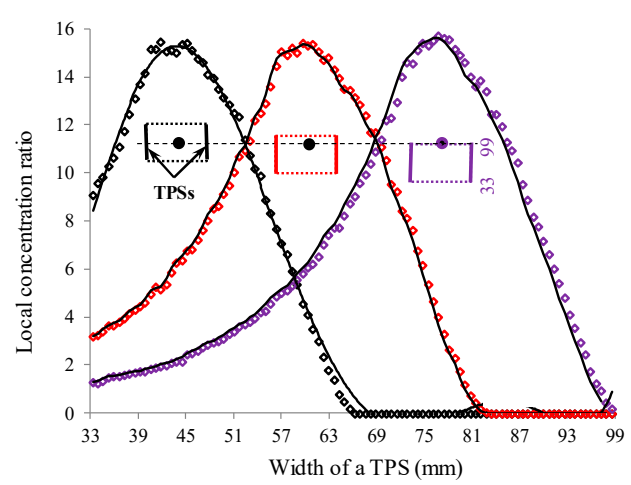

(b)

Figure 8. LCR profiles on: (a) TSS, and (b) TPSs of a rectangular (square) receiver while the trough focus toward the centroid (black graph), centerline of the TNS (purple graph) and in between the centroid and the centerline of the TNS (red graph).

As the ECE moves toward the trough from the first location to the next, the concentrated irradiation gradually shifts from TSS to the TPSs of the ECE. As a result, the downward open parabolic LCR profile of the TSS gradually flattens, and the $C_{\text {peak }}$ and $C_{\text {base }}$ of the TPSs gradually move from the TSS end to the TNS end diminishing the shading (see Figure 8). Significant improvement was observed in MAD of the TSS, which dropped rapidly from 5.44 to 0.94 (see Table 5). As the table shows for the TSS, though the $C_{\text {base }}$ was almost fixed at $9 \times$, the $C_{\text {peak }}$ and $C_{\text {mean }}$ were dropped from $\approx 26$ and $\approx 18 \times$ to $\approx 13.5$ and $11.7 \times$ respectively that caused almost $36 \%$ drop of partial optical efficiency of the 
surface. With the movement of the ECE towards the trough, the estimated partial optical efficiency ratio between the TSS and TPSs was found varied between 1.82 and 0.85 . The total $\eta_{\text {opt }}$ dropped from $33.6 \%$ to $30.5 \%$, which is still higher than the flat and triangular ECEs. The rectangular ECE is even better than the inverted triangular ECE in case of irradiance distribution on the TSS though the $\eta_{\text {opt }}$ is slightly lower (refer the MAD and $\eta_{\text {opt }}$ in Tables 4 and 5). Because of the least MAD of the LCR profile of the TSS at the third focus location, effect of tracking error and rim angle on the optical performance of the ECE was further investigated.

Table 5. Irradiance distribution and optical efficiencies of each surfaces of a rectangular receiver at different defocus conditions.

\begin{tabular}{|c|c|c|c|c|c|c|c|}
\hline $\begin{array}{l}\text { Location of } \\
\text { Focus ( })\end{array}$ & $\begin{array}{c}\text { ECE } \\
\text { Surfaces }\end{array}$ & $\begin{array}{c}C_{\text {base }} \\
(\times)\end{array}$ & $\begin{array}{c}C_{\text {peak }} \\
(\times)\end{array}$ & $\begin{array}{c}\mathrm{C}_{\text {mean }} \\
(\times)\end{array}$ & MAD & $\eta(\%)$ & $\begin{array}{c}\eta_{\text {opt }}=\Sigma \eta \\
(\%)\end{array}$ \\
\hline & TSS & 8.33 & 25.72 & 18.14 & 5.44 & 21.02 & \multirow[b]{2}{*}{33.60} \\
\hline & TPSs & 0 & 15.48 & 4.99 & 5.54 & 11.56 & \\
\hline $\bar{\Omega}$ & TSS & 9.56 & 17.55 & 14.51 & 2.03 & 16.81 & \multirow{2}{*}{32.54} \\
\hline & TPSs & 0 & 15.39 & 6.35 & 4.7 & 14.71 & \\
\hline & TSS & 9.17 & 13.43 & 11.7 & 0.94 & 13.55 & \multirow{2}{*}{30.49} \\
\hline & TPSs & 0.17 & 15.71 & 6.87 & 4.26 & 15.92 & \\
\hline \multicolumn{2}{|c|}{ TNS (for all cases) } & & $\approx 0.88$ & & - & $\approx 1.02$ & - \\
\hline
\end{tabular}

As an example, $\sigma=0.3^{\circ}$ and $\psi=90^{\circ}$ in place of $68^{\circ}$ on the LCR profile and $\eta_{\text {opt }}$ was investigated as shown in Figure 9 and Table 6. Figure 9a shows, tracking error has insignificant effect on the LCR profile of the TSS, and the table shows that the $\mathrm{C}_{\text {mean }}$ and MAD are almost equal to that without tracking error (see Table 6). However, the $\sigma$ adversely affects the LCR profiles of the TPSs (see Figure 9b), and the $\eta_{\text {opt }}$ of the ECE dropped almost by 2 points (see Table 6). Despite this, the $\eta_{\text {opt }}$ of the rectangular ECE is still higher than that of the flat and triangular ones (refer Tables 4 and 6).

On the other hand, light from the increased surface area of the trough of $90^{\circ}$ rim angle (width of the trough increased from $5 \mathrm{~m}$ to $7.36 \mathrm{~m}$ ) was concentrated on the TPSs instead of the TSS. Therefore, though the $C_{\text {mean }}$ of the TSS was almost fixed $(\approx 11.7 \times)$ that was increased almost by 1.8 times for the TPSs (see Table 6). However, the overall $\eta_{\text {opt }}$ is decreased from $28.63 \%$ to $26.98 \%$ that is because the collector geometry for this study was adapted from the LS2 collector for which the $68^{\circ}$ rim angle is optimum.

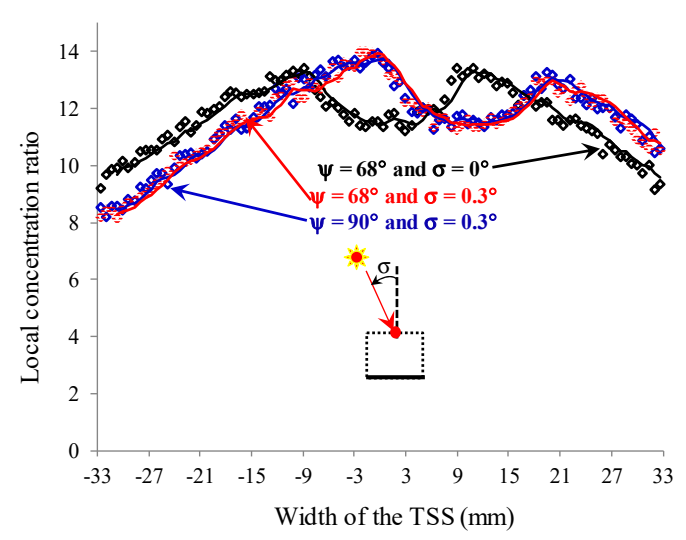

(a)

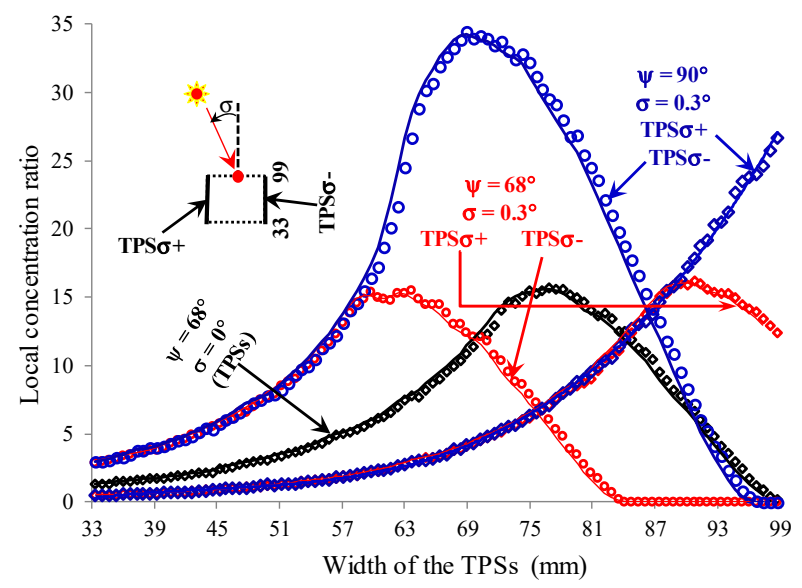

(b)

Figure 9. Effect of rim angle $\left(\psi^{\circ}\right)$ and tracking error $\left(\sigma^{\circ}\right)$ on LCR profile of (a) the TSS, and (b) the TPSs of a rectangular ECE. (In the figure, TPS at the tracking error side called TPS $\sigma+$ and the opposite one called TPS $\sigma-)$. 
Table 6. Effect of tracking error $\left(\sigma^{\circ}\right)$ and rim angle $\left(\psi^{\circ}\right)$ on the optical performance of a rectangular receiver while the trough focus toward the centerline of the TNS, $\square$.

\begin{tabular}{|c|c|c|c|c|c|c|c|c|}
\hline$\left({ }^{\circ}\right)$ & $\sigma\left(^{\circ}\right)$ & ECE Surfaces & $\begin{array}{c}C_{\text {base }} \\
(\times)\end{array}$ & $\begin{array}{c}C_{\text {peak }} \\
(\times)\end{array}$ & $\begin{array}{c}C_{\text {mean }} \\
(\times)\end{array}$ & MAD & $\eta(\%)$ & $\eta_{\text {opt }}=\Sigma \eta(\%)$ \\
\hline \multirow{6}{*}{68} & \multirow{2}{*}{0} & TSS & 9.17 & 13.43 & 11.7 & 0.94 & 13.55 & \multirow{2}{*}{30.49} \\
\hline & & TPSs & 0.17 & 15.71 & 6.87 & 4.26 & 15.92 & \\
\hline & \multirow{3}{*}{0.3} & TSS & 8.2 & 13.95 & 11.68 & 1.05 & 13.53 & \multirow{4}{*}{28.63} \\
\hline & & $\mathrm{TPS}_{\sigma+}$ & 0.49 & 16.21 & 5.81 & 4.76 & 6.73 & \\
\hline & & $\mathrm{TPS}_{\sigma-}$ & 0 & 15.47 & 6.34 & 4.56 & 7.35 & \\
\hline & \multicolumn{2}{|c|}{ TNS (for both $\sigma$ ) } & & $\approx 0.88$ & & - & $\approx 1.02$ & \\
\hline \multirow{4}{*}{90} & \multirow{4}{*}{0.3} & TSS & 8.13 & 13.98 & 11.68 & 1.05 & 9.19 & \multirow{4}{*}{26.98} \\
\hline & & $\mathrm{TPS}_{\sigma+}$ & 0.47 & 26.65 & 6.82 & 6.00 & 5.37 & \\
\hline & & $\mathrm{TPS}_{\sigma-}$ & 0 & 34.5 & 14.9 & 9.98 & 11.73 & \\
\hline & & TNS & & $\approx 0.88$ & & - & $\approx 0.69$ & \\
\hline
\end{tabular}

\subsection{Rectangle on Semi-Circle (RSc) ECE}

A Rectangle on Semi-circle (RSc) ECE was formed replacing the flat TSS of the rectangular ECE with a semicircular one because of high partial optical efficiency of circular TSSs were estimated for the circular and semicircular ECES. The LCR profiles were developed for two locations of the trough focus on the ECE: (a) focus on the center of the semi-circular TSS, and (b) on the TNS of the ECE as shown in Table 7.

Table 7. Effect of tracking error $\left(\sigma^{\circ}\right)$ and rim angle $\left(\psi^{\circ}\right)$ on the optical performance of the RSc ECE.

\begin{tabular}{|c|c|c|c|c|c|c|c|c|c|}
\hline $\begin{array}{l}\text { Location of } \\
\text { Focus (0) }\end{array}$ & $\psi\left({ }^{\circ}\right)$ & $\sigma\left(^{\circ}\right)$ & $\begin{array}{c}\text { ECE } \\
\text { Surfaces }\end{array}$ & $\begin{array}{c}C_{\text {base }} \\
(\times)\end{array}$ & $\underset{(\times)}{C_{\text {peak }}}$ & $\begin{array}{c}\mathrm{C}_{\text {mean }} \\
(\times)\end{array}$ & MAD & $\eta(\%)$ & $\underset{(\%)}{\eta_{\text {opt }}=\Sigma \eta}$ \\
\hline & \multirow{6}{*}{68} & \multirow{2}{*}{0} & TSS & 1.26 & 63.44 & 43.01 & 15.46 & 78.3 & \multirow[b]{2}{*}{79.32} \\
\hline & & & TPSs & 0 & 0 & 0 & - & - & \\
\hline & & \multirow{3}{*}{0.3} & TSS & 0 & 73.37 & 40.16 & 19.42 & 74.93 & \multirow{4}{*}{77.47} \\
\hline & & & TPS $\sigma+$ & 0 & 11.89 & 2.63 & 3.28 & 1.52 & \\
\hline & & & TPS $\sigma-$ & 0 & 0 & 0 & - & - & \\
\hline & & \multicolumn{2}{|c|}{ TNS (for both $\sigma$ ) } & & \multicolumn{2}{|c|}{$\approx 0.88$} & - & $\approx 1.02$ & \\
\hline & \multirow{6}{*}{90} & \multirow{2}{*}{0} & TSS & 44.74 & 81.55 & 59.96 & 8.83 & 74.16 & \multirow{2}{*}{78.31} \\
\hline & & & TPSs & 0 & 20.09 & 4.39 & 5.18 & 3.46 & \\
\hline & & \multirow{3}{*}{0.3} & TSS & 0.03 & 95.61 & 56.23 & 15.57 & 69.54 & \multirow{4}{*}{77.23} \\
\hline & & & TPS $\sigma+$ & 0 & 30.01 & 17.80 & 8.54 & 7.00 & \\
\hline & & & TPS $\sigma-$ & 0 & 0 & 0 & - & 0.00 & \\
\hline & & \multicolumn{2}{|c|}{ TNS (for both $\sigma$ ) } & & \multicolumn{2}{|l|}{$\approx 0.88$} & - & $\approx 0.69$ & \\
\hline & \multirow{6}{*}{68} & \multirow[b]{2}{*}{0} & TSS & 23.07 & 33.88 & 29.91 & 1.99 & 54.45 & \multirow{2}{*}{67.11} \\
\hline & & & TPSs & 0 & 15.58 & 10.05 & 3.95 & 11.64 & \\
\hline & & \multirow{3}{*}{0.3} & TSS & 22.08 & 49.19 & 30.36 & 6.38 & 55.27 & \multirow{4}{*}{64.84} \\
\hline & & & TPS $\sigma+$ & 0 & 16.01 & 10.23 & 3.99 & 5.93 & \\
\hline & & & $\operatorname{TPS} \sigma-$ & 0 & 13.71 & 4.05 & 4.41 & 2.35 & \\
\hline & & \multicolumn{2}{|c|}{ TNS (for both $\sigma$ ) } & & \multicolumn{2}{|l|}{$\approx 0.88$} & - & $\approx 1.02$ & \\
\hline & \multirow{6}{*}{90} & \multirow{2}{*}{0} & TSS & 23.07 & 33.92 & 29.91 & 1.99 & 36.99 & \multirow{2}{*}{55.6} \\
\hline & & & TPSs & 0.00 & 32.77 & 22.77 & 6.51 & 17.92 & \\
\hline & & \multirow{3}{*}{0.3} & TSS & 22.09 & 73.26 & 31.71 & 8.11 & 39.22 & \multirow{4}{*}{52.37} \\
\hline & & & TPS $\sigma+$ & 1.5 & 29.77 & 12.23 & 5.61 & 4.81 & \\
\hline & & & TPS $\sigma-$ & 0 & 34.37 & 19.43 & 11.17 & 7.65 & \\
\hline & & \multicolumn{2}{|c|}{ TNS (for both $\sigma$ ) } & & $\approx 0.88$ & & - & $\approx 0.69$ & \\
\hline
\end{tabular}


At the first focus location, the optical performance of the RSc ECE with a $68^{\circ}$ rim angle trough was found similar to that of a semicircular one (see Table 7 and Figure 10a). Increase of trough rim angle from $68^{\circ}$ to $90^{\circ}$ rather decreases the overall optical efficiency of the ECE by $\approx 1 \%$ from $79.3 \%$. However, the LCR profile of the TSS improves significantly as the MAD drops from 16.7 to 8.83 , $\mathrm{C}_{\text {mean }}$ increases drastically from $43 \times$ to $60 \times$ and the TPSs contribute $3.46 \%$ of optical efficiency with 5.18 MAD (see Table 7 and Figure 10c).

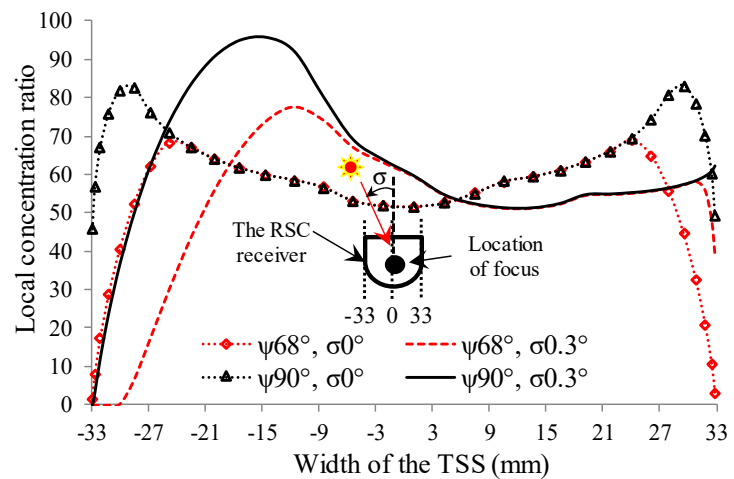

(a)

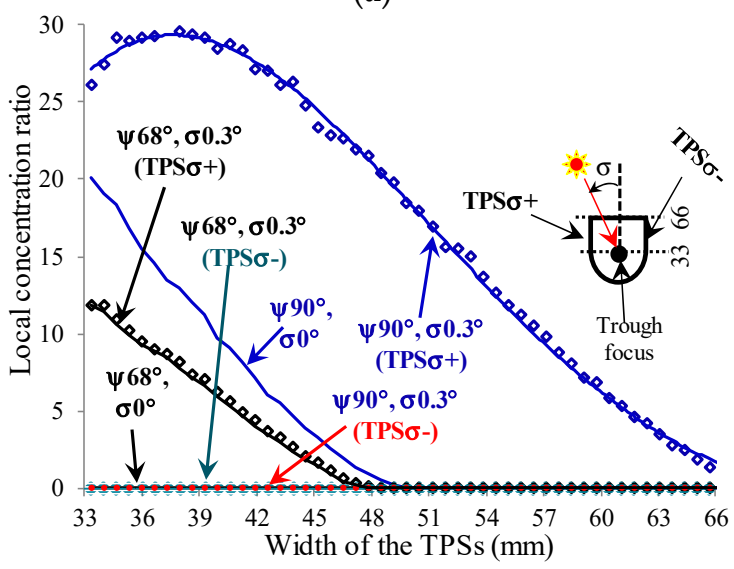

(c)

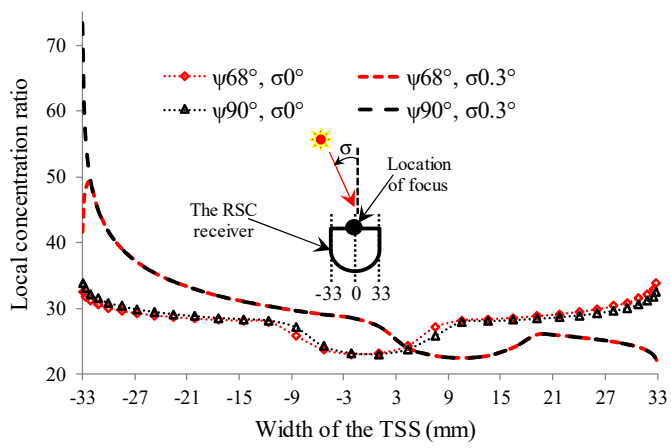

(b)

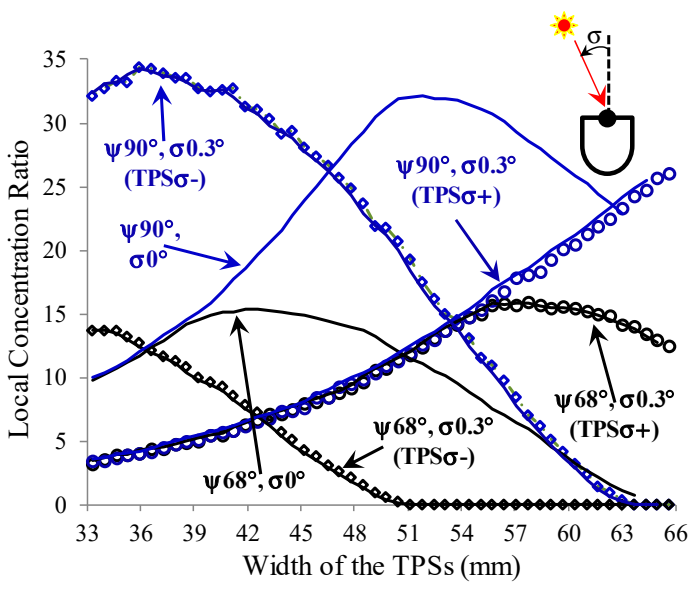

(d)

Figure 10. LCR profile around the RSc ECE orientation scheme for $68^{\circ}$ and $90^{\circ}$ rim angle trough $(\psi)$, and with and without $0.3^{\circ}$ tracking error $(\sigma)$ : (a) LCR profile on the curved TSS while the trough focus at the centre of curvature, (b) profile on the curved TSS while the trough focus at the TNS, (c) profile on the TPSs while the trough focus at the centre of the TSS and (d) profile on the TPSs while the trough focus at the TNS.

An induced tacking error of $0.3^{\circ}$ caused a reduction $\eta_{\text {opt }}$ by $1-2 \%$ for both troughs, and adversely affected the light distribution. The adversity on the LCR profile was observed to be much higher for the ECE with a trough of $90^{\circ} \psi$ than that of $68^{\circ}$ one (see Table 7).

At the second focus location, the defocus effect causes a drastic reduction in the $\eta_{\text {opt }}$, which was estimated to be $12 \%+$ for the $68^{\circ}$ trough rim angle and $22 \%+$ for the $90^{\circ}$ trough rim angle with or without $0.3^{\circ}$ tracking error (see Table 7). In general, the defocus effect improved the LCR distribution of the TSS significantly; the LCR profile fairly flatten (see Figure 10b) and the MAD dropped to 2 for both trough rim angles, and increased the TPSs' contribution to the $\eta_{\text {opt }}$ considerably (see Table 7).

Interestingly, though there was an overall drop in the $\eta_{\text {opt }}$ by around $3 \%$, and a $0.3^{\circ}$ tracking error was observed to increase the $\mathrm{C}_{\text {mean }}$ and partial optical efficiency of the TSS. The partial optical efficiency of the TSS was increased by $0.85 \%$ and $2.23 \%$ respectively for the troughs of rim angle $68^{\circ}$ 
and $90^{\circ}$ (see Table 7). The improvement in the uniformity of the LCR profile due of the induced defocus was gone because of the tracking error (see Figure 10d and Table 7).

\section{Discussion}

In this section, a comparison among the studied ECEs is made based on their relative optical performance. This study found that the optical efficiency of the ECEs with curved TSS (i.e., circular, semicircular and RSc) is much higher than that of linear TSS (i.e., flat, triangular, inverted triangular and rectangular). The reason is the incidence angle dependent light absorptance of the ECE material. Average incidence angle of the concentrated light on the linear TSS is much higher than that of the curved one, and causes cosine loss in light absorptance. ECE materials with incidence angle independent light absorptance would increase the optical efficiency of the collector.

In the event of defocus, as well as tracking error, a part of the concentrated light usually escape the TSS of the ECE. Resultant optical loss and the overall optical efficiency relies on the interceptance of this light by any active surface like TPS of the ECE. The rectangular and RSc type ECEs with TPSs are more likely to exhibit better interceptance to this escaped light than the flat, semicircular and triangular ECEs. However, defocus event improves the uniformity of the LCR profile (decrease the MAD) of the TSS, though the $\mathrm{C}_{\text {mean }}$ of the surface decreases.

Being flat and parallel to the trough aperture, the TNS of the semicircular, inverted triangular, rectangular and RSC ECEs allows uniform one sun photovoltaic application. Other than these, the direct sun incident on the curved surface of the circular ECE and inclined surfaces of the triangular ECE are likely to be highly non-uniform and causes shading effect to photovoltaic application.

Although the flat ECE has the highest $C_{\text {peak }}$ and $C_{\text {mean }}$ at the ideal optical condition, being a single surface (TSS only), it is the most vulnerable to any optical loss event like defocus and tracking errors. In addition to this, the HTF has the least contact area with the TSS, and therefore, the cooling effect should be the least compared to the rest of the studied ECEs in general.

\section{Conclusions}

Characteristics of the irradiance distribution around the outer surface of different ECE orientation schemes and optical efficiency of a PTCC were investigated computationally applying MCRT technique. The ECE orientation schemes include a circular, semicircular, flat, triangular, inverted triangular, rectangular and RSc. The surfaces of the ECEs are called TSS (surface at the trough end), TNS (opposite to the TSS) and TPS (perpendicular to the trough aperture). The irradiance profile around the ECEs was calculated as LCR profile, from which $\mathrm{C}_{\text {base }}, \mathrm{C}_{\text {peak }}, \mathrm{C}_{\text {mean }}$, uniformity of the LCR profile as $\mathrm{MAD}$, and $\eta_{\text {opt }}$ were calculated. The effect of ECE defocus, sun tracking error and trough rim angle were also investigated for selective cases. From this study, following conclusions can be made:

(i) The ECE orientation schemes (circular, semicircular and RSc) with curved TSS showed much higher $\eta_{\text {opt }}(>79 \%)$ than those (flat, triangular, inverted triangular and rectangular) with linear TSS ( $\eta_{\text {opt }}$ ranging between $25 \%$ and $38 \%$ ) in ideal conditions (i.e., no defocus and tracking error) with a trough of $68^{\circ}$ rim angle

(ii) Among the linear TSS group, the optical efficiency was calculated to be highest for the inverted triangular ECE (around 37\%), lowest for the flat and triangular ECEs $(\approx 26 \%)$, and somewhere in middle for the rectangular ECE (in between $30.5 \%$ and $33.5 \%$ ).

(iii) The MAD of the TSS of the rectangular ECE was estimated to be the lowest, ranging from 0.94 at defocus condition to 5.44 at ideal condition. In the event of tracking error and with a trough of higher rim angle, the MAD was found increased insignificantly, only increased to 1.05 from 0.94. That is the uniformity of the irradiance distribution (i.e., the LCR profile) on the TSS of a rectangular ECE was found to be the best among the studied ECE orientation schemes.

(iv) In the event of defocus and tracking error, a significant portion of the concentrated light was observed to be intercepted by the TPSs. Therefore, based on this study, ECEs among the curved 
TSS group, it is clear that the RSc would be more efficient than the circular and semicircular ones. Similarly, among the linear TSS group the rectangular one would be more efficient than the remaining ECEs of the group.

(v) Sun tracking error and the ECE defocus have negative effect on the optical efficiency of the collector in general. However, ECE defocus helps to reduce the MAD that is the non-uniformity of the LCR profile of the TSS.

(vi) Study of the effect of $90^{\circ}$ trough rim angle over a $68^{\circ}$ one for the rectangular and RSc ECEs implied that there is an optimum rim angle for each collector design; trough rim angle larger than that would increase the total concentrated light on the ECE and, for few instances, the uniformity of the LCR profile of the TSS, but will decrease the optical efficiency of the collector.

The current study provides useful information for designing optically efficient ECE for a parabolic trough concentrating solar collector. The current study will be continued to investigate the effect of structural deformity and light incident angle on the optical performance, and relative thermal performance of the ECEs under certain environmental conditions. The daily and year round energy potential of the optimum ECE is worthy to be exploring and will be a step forward towards the energy sustainability.

Author Contributions: M.I. conceived, designed and accomplished the research, and drafted the article under the principle supervision of A.K., who was the leader of the research team. P.Y. was the associate supervisor for the research program.

Funding: This article is supported by QUT research grant.

Acknowledgments: The authors like to acknowledge the support provided by Suvash Chandra Saha, Senior Lecturer at University of Technology Sydney, during conducting the research.

Conflicts of Interest: No known conflicts of interest.

\section{Nomenclature}

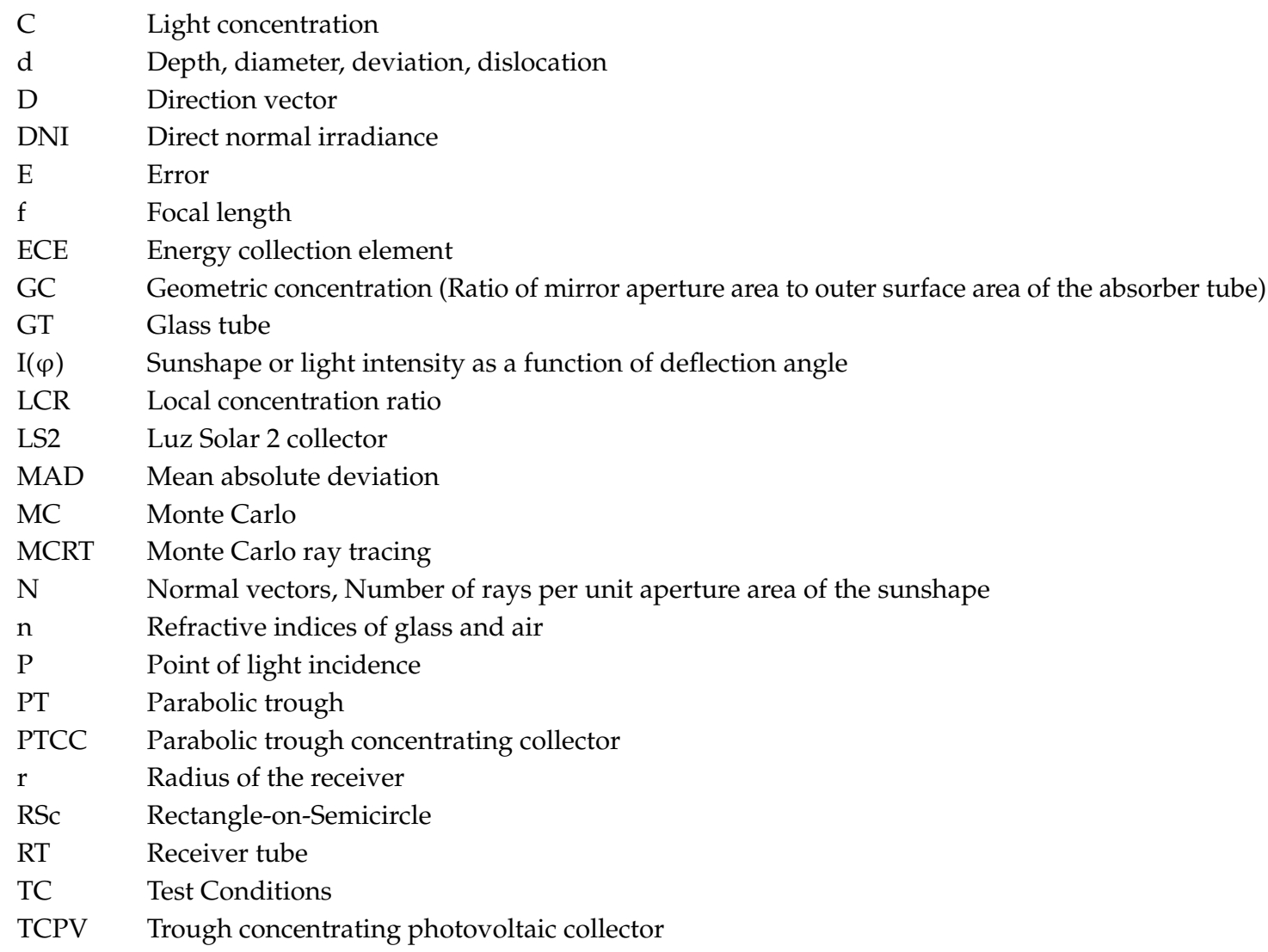




\section{Nomenclature}

TCPVT Trough concentrating hybrid photovoltaic/thermal collector

$X, Y, Z \quad$ Cartesian coordinate system

$X, r, \beta \quad$ Polar coordinate system

Symbols

$\alpha \quad$ Absorptance of ECE material

$\eta_{\text {opt }} \quad$ Optical efficiency

$\psi \quad$ Rim angle $\left(^{\circ}\right)$ of the mirror

$\varphi \quad$ Deflection angle of sun

$\theta \quad$ Angle of light incidence on the ECE

$\rho_{\mathrm{PT}} \quad$ Reflectance of mirror

$\tau_{\mathrm{GT}} \quad$ Transmittance of glass

$\times \quad$ Times

\section{Suffixes}

base Base

est Estimated

$1 \quad$ Local

mean Mean

o $\quad$ Outer or outside

peak Peak

\section{References}

1. Burgess, G.; Scott, P.; Pye, J. Spherical and asymmetric mirror panels for paraboloidal concentrators. Presented at the 3rd International Solar Energy Society Conference-Asia Pacific Region (ISES-AP-08), Sydney, Australia, 4-6 March 2008.

2. Kalogirou, S.A. (Ed.) Solar Energy Engineering: Processes and Systems. In Solar Energy Engineering; Academic Press: Boston, MA, USA, 2009; pp. 1-48.

3. Yilmaz, İ.H. Optimization of an integral flat plate collector-storage system for domestic solar water heating in Adana. Anadolu Univ. J. Sci. Technol. A Appl. Sci. Eng. 2018, 19, 165-176. [CrossRef]

4. Yllmaz, İ.H.; Mwesigye, A. Modeling, simulation and performance analysis of parabolic trough solar collectors: A comprehensive review. Appl. Energy 2018, 225, 135-174. [CrossRef]

5. Price, H.; Lupfert, E.; Kearney, D.; Zarza, E.; Cohen, G.; Gee, R.; Mahoney, R. Advances in Parabolic Trough Solar Power Technology. J. Sol. Energy Eng. 2002, 124, 109-125. [CrossRef]

6. Fernández-García, A.; Zarza, E.; Valenzuela, L.; Pérez, M. Parabolic-trough solar collectors and their applications. Renew. Sustain. Energy Rev. 2010, 14, 1695-1721. [CrossRef]

7. Mousazadeh, H.; Keyhani, A.; Javadi, A.; Mobli, H.; Abrinia, K.; Sharifi, A. A review of principle and sun-tracking methods for maximizing solar systems output. Renew. Sustain. Energy Rev. 2009, 13, 1800-1818. [CrossRef]

8. Parida, B.; Iniyan, S.; Goic, R. A review of solar photovoltaic technologies. Renew. Sustain. Energy Rev. 2011, 15, 1625-1636. [CrossRef]

9. Timilsina, G.R.; Kurdgelashvili, L.; Narbel, P.A. Solar energy: Markets, economics and policies. Renew. Sustain. Energy Rev. 2012, 16, 449-465. [CrossRef]

10. Tyagi, V.V.; Kaushik, S.C.; Tyagi, S.K. Advancement in solar photovoltaic/thermal (PV/T) hybrid collector technology. Renew. Sustain. Energy Rev. 2012, 16, 1383-1398. [CrossRef]

11. Pavlović, T.M.; Radonjić, I.S.; Milosavljević, D.D.; Pantić, L.S. A review of concentrating solar power plants in the world and their potential use in Serbia. Renew. Sustain. Energy Rev. 2012, 16, 3891-3902. [CrossRef]

12. Devabhaktuni, V.; Alam, M.; Depuru, S.S.S.R.; Green, R.C.; Nims, D.; Near, C. Solar energy: Trends and enabling technologies. Renew. Sustain. Energy Rev. 2013, 19, 555-564. [CrossRef]

13. Cabrera, F.J.; Fernández-García, A.; Silva, R.M.P.; Pérez-García, M. Use of parabolic trough solar collectors for solar refrigeration and air-conditioning applications. Renew. Sustain. Energy Rev. 2013, 20, $103-118$. [CrossRef] 
14. Zhang, H.L.; Baeyens, J.; Degrève, J.; Cacères, G. Concentrated solar power plants: Review and design methodology. Renew. Sustain. Energy Rev. 2013, 22, 466-481. [CrossRef]

15. Mojiri, A.; Taylor, R.; Thomsen, E.; Rosengarten, G. Spectral beam splitting for efficient conversion of solar energy-A review. Renew. Sustain. Energy Rev. 2013, 28, 654-663. [CrossRef]

16. Jebasingh, V.K.; Herbert, G.M.J. A review of solar parabolic trough collector. Renew. Sustain. Energy Rev. 2016, 54, 1085-1091. [CrossRef]

17. IEA. Renewable Energy Essentials: Concentrating Solar Thermal Power. 2009. Available online: https:/ / webstore.iea.org/renewable-energy-essentials-concentrating-solar-thermal-power (accessed on 1 December 2018).

18. Dudley, V.E.; Kolb, G.J.; Mahoney, A.R.; Mancini, T.R.; Matthews, C.W.; Sloan, M.; Kearney, D. Test results: SEGS LS-2 solar collector, SAND-94-1884; Other: ON: DE95010682; TRN: TRN: 95:004741 United StatesOther: ON: DE95010682; TRN: TRN: 95:004741Thu Feb 18 07:35:13 EST 2010OSTI as DE95010682SNL; SCA: 141000; PA: EDB-95:095446; NTS-95:019046; ERA-20:021131; SN: 95001377800; TVI: 10724English. 1994. Available online: http:/ /large.stanford.edu/publications/coal/references/troughnet/solarfield/docs/segs_ls2_solar_ collector.pdf (accessed on 8 September 2013).

19. Forristall, R. Heat Transfer Analysis and Modeling of a Parabolic Trough Solar Receiver Implemented in Engineering Equation Solver, National Renewable Energy Laboratory, 1617 Cole Boulevard, Golden, Colorado 80401-3393, Technical report No. NERL/TP-550-34169. NREL/TP-550-34169. 2003. Available online: http:/ / fac.ksu.edu.sa/sites/default/files/34169.pdf (accessed on 24 April 2013).

20. Lüpfert, E.; Zarza, E.; Geyer, M.; Nava, P.; Langenkamp, J.; Schiel, W.; Esteban, A.; Osuna, R.; Mandelberg, E. Euro Trough Collector Qualification Complete-Performance Test Results from PSA. In Proceedings of the ISES Solar World Congress, Göteborg, Sweden, 14-19 June 2003.

21. Anton, I.; Sala, G.; Arboiro, J.C.; Monedero, J.; Valera, P. Effect of the optical performance on the output put power of the EUCLIDES ${ }^{\mathrm{TM}}$ array. Presented at the 16th European Photovoltaics Solar Energy Conference, Glasgow, UK, 1-5 May 2000.

22. Sala, G.; Anton, I.; Arboiro, J.C.; Luque, A.; Camblor, E.; Mera, E.; Gasson, M.; Cendagorta, M.; Valera, P.; Friend, M.P.; et al. The 480 kW (p) EUCLIDESTM -THERMIE Power Plant: Installation Set-Up and First Results. Presented at the 16th European Photovoltaic Solar Energy Conference, Glasgow, UK, 1-5 May 2000.

23. Coventry, J.S. Performance of a concentrating photovoltaic/thermal solar collector. Sol. Energy 2005, 78, 211-222. [CrossRef]

24. Coventry, J.S.; Franklin, E.; Blakers, A. Thermal and electrical performance of a concentrating PV/Thermal collector: Results from the ANU CHAPS collector. Presented at the ANZSES Solar Energy Conference, Newcastle, Australia, 27-29 November 2002.

25. Li, M.; Li, G.L.; Ji, X.; Yin, F.; Xu, L. The performance analysis of the Trough Concentrating Solar Photovoltaic/Thermal system. Energy Convers. Manag. 2011, 52, 2378-2383. [CrossRef]

26. Srivastava, S.; Reddy, K.S. Simulation studies of thermal and electrical performance of solar linear parabolic trough concentrating photovoltaic system. Solar Energy 2017, 149, 195-213. [CrossRef]

27. Calise, F.; Palombo, A.; Vanoli, L. A finite-volume model of a parabolic trough photovoltaic/thermal collector: Energetic and exergetic analyses. Energy 2012, 46, 283-294. [CrossRef]

28. Calise, F.; Vanoli, L. Parabolic Trough Photovoltaic/Thermal Collectors: Design and Simulation Model. Energies 2012, 5, 4186-4208. [CrossRef]

29. Bernardo, L.R.; Perers, B.; Håkansson, H.; Karlsson, B. Performance evaluation of low concentrating photovoltaic/thermal systems: A case study from Sweden. Solar Energy 2011, 85, 1499-1510. [CrossRef]

30. Baig, H.; Heasman, K.C.; Mallick, T.K. Non-uniform illumination in concentrating solar cells. Renew. Sustain. Energy Rev. 2012, 16, 5890-5909. [CrossRef]

31. Coventry, J.S.; Franklin, E.; Blakers, A. Performance of the CHAPS collectors. Presented at the ANZSES Solar Energy Conference, Melbourne, Australia, 26-29 November 2003.

32. Blakers, A.; Coventry, J.S.; Franklin, E.; Dennis, M.; Cotsell, J.; Holly, C.; Smeltink, J. Solar Concentrators at ANU. Presented at the International Solar Concentrator Conference for the Generation of Electricity or Hydrogen, Alice Springs, Australia, 10-14 November 2003.

33. Thomas, A.; Guven, H.M. Parabolic trough concentrators-Design, construction and evaluation. Energy Convers. Manag. 1993, 34, 401-416. [CrossRef] 
34. Thomas, A.; Guven, H.M. Effect of optical errors on flux distribution around the absorber tube of a parabolic trough concentrator. Energy Convers. Manag. 1994, 35, 575-582. [CrossRef]

35. Hassan, K.-E.; El-Refaie, M.F. Theoretical performance of cylindrical parabolic solar concentrators. Sol. Energy 1973, 15, 219-244. [CrossRef]

36. Evans, D.L. On the performance of cylindrical parabolic solar concentrators with flat absorbers. Sol. Energy 1977, 19, 379-385. [CrossRef]

37. Daly, J.C. Solar concentrator flux distributions using backward ray tracing. Appl. Opt. 1979, 18, $2696-2699$. [CrossRef] [PubMed]

38. Nicolás, R.O.; Durán, J.C. Generalization of the two-dimensional optical analysis of cylindrical concentrators. Sol. Energy 1980, 25, 21-31. [CrossRef]

39. Durán, J.C.; Nicolás, R.O. Development and applications of a two-dimensional optical analysis of non-perfect cylindrical concentrators. Sol. Energy 1985, 34, 257-269. [CrossRef]

40. Jeter, S.M. Calculation of the concentrated flux density distribution in parabolic trough collectors by a semifinite formulation. Sol. Energy 1986, 37, 335-345. [CrossRef]

41. Jeter, S.M. The Distribution of Concentrated Solar Radiation in Paraboloidal Collectors. J. Sol. Energy Eng. 1986, 108, 219-225. [CrossRef]

42. Jeter, S.M. Analytical determination of the optical performance of practical parabolic trough collectors from design data. Sol. Energy 1987, 39, 11-21. [CrossRef]

43. Kalogirou, S.A.; Lloyd, S.; Ward, J.; Eleftheriou, P. Design and performance characteristics of a parabolic-trough solar-collector system. Appl. Energy 1994, 47, 341-354. [CrossRef]

44. Shortis, M.R.; Johnston, G.H.G. Photogrammetry: An Available Surface Characterization Tool for Solar Concentrators, Part I: Measurements of Surfaces. J. Sol. Energy Eng. 1996, 118, 146-150. [CrossRef]

45. Shortis, M.; Johnston, G. Photogrammetry: An Available Surface Characterization Tool for Solar Concentrators, Part II: Assessment of Surfaces. J. Sol. Energy Eng. 1997, 119, 286-291. [CrossRef]

46. Pottler, K.; Lüpfert, E.; Johnston, G.H.G.; Shortis, M.R. Photogrammetry: A Powerful Tool for Geometric Analysis of Solar Concentrators and Their Components. J. Sol. Energy Eng. 2005, 127, 94-101. [CrossRef]

47. Riffelmann, K.-J.; Neumann, A.; Ulmer, S. Performance enhancement of parabolic trough collectors by solar flux measurement in the focal region. Sol. Energy 2006, 80, 1303-1313. [CrossRef]

48. Ergashev, S. Radiation Flux Distribution in the Focal Plane of a Parabolic-Cylindrical Concentrator. Appl. Sol. Energy C/C Geliotekhnika 2006, 42, 29.

49. Lüpfert, E.; Pottler, K.; Ulmer, S.; Riffelmann, K.-J.; Neumann, A.; Schiricke, B. Parabolic Trough Optical Performance Analysis Techniques. J. Sol. Energy Eng. 2006, 129, 147-152. [CrossRef]

50. Bader, R.; Steinfeld, A. A Solar Trough Concentrator for Pill-Box Flux Distribution Over a CPV Panel. J. Sol. Energy Eng. 2010, 132, 014501. [CrossRef]

51. Xiao, J.; He, Y.; Cheng, Z.; Tao, Y.; Xu, R. Performance analysis of parabolic trough solar collector. J. Eng. Thermophys. 2009, 30, 729-733.

52. Grena, R. Optical simulation of a parabolic solar trough collector. Int. J. Sustain. Energy 2010, 29, $19-36$. [CrossRef]

53. Yang, B.; Zhao, J.; Xu, T.; Zhu, Q. Calculation of the Concentrated Flux Density Distribution in Parabolic Trough Solar Concentrators by Monte Carlo Ray-Trace Method. In Proceedings of the 2010 Symposium on Photonics and Optoelectronics, Chengdu, China, 19-21 June 2010; pp. 1-4.

54. Jiang, S.; Hu, P.; Mo, S.; Chen, Z. Optical modeling for a two-stage parabolic trough concentrating photovoltaic/thermal system using spectral beam splitting technology. Sol. Energy Mater. Sol. Cells 2010, 94, 1686-1696. [CrossRef]

55. Cheng, Z.D.; He, Y.L.; Xiao, J.; Tao, Y.B.; Xu, R.J. Three-dimensional numerical study of heat transfer characteristics in the receiver tube of parabolic trough solar collector. Int. Commun. Heat Mass Transf. 2010, 37, 782-787. [CrossRef]

56. Yung, C.-F.; Yeh, H.-Y.; Lee, C.-D.; Wu, J.-L.; Zhou1, P.-C.; Feng, J.-C.; Wang, H.-X.; Peng, S.J. Optimal regional pole placement for sun tracking control of high-concentration photovoltaic (HCPV) systems: Case study. Opt. Control Appl. Methods 2010, 31, 581-591. [CrossRef]

57. He, Y.-L.; Xiao, J.; Cheng, Z.-D.; Tao, Y.-B. A MCRT and FVM coupled simulation method for energy conversion process in parabolic trough solar collector. Renew. Energy 2011, 36, 976-985. [CrossRef] 
58. Cheng, Z.D.; He, Y.L.; Cui, F.Q.; Xu, R.J.; Tao, Y.B. Numerical simulation of a parabolic trough solar collector with nonuniform solar flux conditions by coupling FVM and MCRT method. Sol. Energy 2012, 86, 1770-1784. [CrossRef]

59. Cheng, Z.D.; He, Y.L.; Cui, F.Q. A new modelling method and unified code with MCRT for concentrating solar collectors and its applications. Appl. Energy 2013, 101, 686-698. [CrossRef]

60. Cheng, Z.D.; He, Y.L.; Cui, F.Q.; Du, B.C.; Zheng, Z.J.; Xu, Y. Comparative and sensitive analysis for parabolic trough solar collectors with a detailed Monte Carlo ray-tracing optical model. Appl. Energy 2014, 115, 559-572. [CrossRef]

61. Wang, Y.; Liu, Q.; Lei, J.; Jin, H. Performance analysis of a parabolic trough solar collector with non-uniform solar flux conditions. Int. J. Heat Mass Transf. 2015, 82, 236-249. [CrossRef]

62. Zou, B.; Dong, J.; Yao, Y.; Jiang, Y. A detailed study on the optical performance of parabolic trough solar collectors with Monte Carlo Ray Tracing method based on theoretical analysis. Sol. Energy 2017, 147, 189-201. [CrossRef]

63. Kabakov, V.I.; Levin, L.B. A choice of the position of receiver with photocells in parabolic trough concentrator. Sol. Energy Mater. Sol. Cells 1994, 33, 45-49. [CrossRef]

64. Islam, M.; Miller, S.; Yarlagadda, P.K.; Karim, A. Investigation of the effect of physical and optical factors on the optical performance of a parabolic trough collector. Energies 2017, 10, 1907. [CrossRef]

65. Zemax ${ }^{\circledR}$. Optical Design Program, User's Manual; Radiant Zemax LLC: Bellevue, WA, USA, 2011. Available online: www.radiantzemax.com (accessed on 23 April 2013).

66. Buie, D.; Monger, A.G.; Dey, C.J. Sunshape distributions for terrestrial solar simulations. Sol. Energy 2003, 74, 113-122. [CrossRef]

67. Buie, D.; Dey, C.J.; Bosi, S. The effective size of the solar cone for solar concentrating systems. Sol. Energy 2003, 74, 417-427. [CrossRef]

68. Buie, D.; Monger, A.G. The effect of circumsolar radiation on a solar concentrating system. Sol. Energy 2004, 76, 181-185. [CrossRef]

(C) 2018 by the authors. Licensee MDPI, Basel, Switzerland. This article is an open access article distributed under the terms and conditions of the Creative Commons Attribution (CC BY) license (http:/ / creativecommons.org/licenses/by/4.0/). 